\title{
Moving Load Robot Using Wifi Network and Android Based
}

\author{
Yuda Irawan \\ Department of Information System, STMIK Hang Tuah Pekanbaru, Pekanbaru, Indonesia \\ Email: yudairawan89@gmail.com
}

\begin{abstract}
A robot is a mechanical device that can perform physical tasks, either using human supervision or control by using predefined programs. In this research, a robot prototype will be designed that can move goods in the form of glasses and plates from one place to another using controls from Android. This system or robot can work as expected, the system is capable of mapping based on the path that has been made. The method used in developing this robot is the prototype method so that the robot is built according to the needs that the user wants directly and can be revised according to the user's wishes after making the design. The robot is also able to take a glass / plate from the table to move it to the desired place. From the experiments that have been carried out as many as $\mathbf{1 0}$ times on the movement of the robot to move glasses and plates, the research got a value of $50 \%$ perfect success rate, $30 \%$ who failed in the middle of the road, and $20 \%$ who failed to do the mapping of all the series of experiments that must be passed.
\end{abstract}

Keywords - Moving Load Robot, Android, Arduino Uno.

\section{INTRODUCTION}

Rapid technological developments can be seen in the field of computer-based technology which affects the social, banking, military, health services, entrepreneurship and almost all large and small companies also use it was studied by zhu [1]. One of them is the development of technology which refers to an automation system where the human role is replaced by machines was studied by dong [2].

A robot is a mechanical device that can perform physical tasks, either using human supervision or control by using predefined programs was studied by kosuge [3]. The robot is clarified into 4 parts, including Humanoid Robot, NonMobile Robot, Mobile Robot, and a combination of NonMobile Robot and Mobile Robot was studied by irawan [4]. The robots that are developing at this time are humanoid robots where this type of robot is developed to help human work was studied by bahrami [5]. The use of robots really helps the work of operators where operators no longer need to move goods manually, because robots can replace the role of humans to move goods was studies by zhu [6]. At the Muara Bulian District Court, the robot will help with cleaning service (CS) work so that it will be more efficient when moving goods in this case in the form of glasses and plates used by employees was studied by zhou [7].

From the results of interviews with the Secretary of the Muara Bulian District Court, it was found that plates and glasses used by employees were often not returned to the pantry was studied by choi [8]. Cleaning service staff rarely go around to pick up glasses and plates. In this condition, the cleaning service officers only take the glasses and plates in the morning and sometimes the glasses and plates are left alone until the morning was studied by nascimento [9].

In the development of science and technology, especially in the fields of computers and electronics, people can feel a lot, one of which is in the fields of industry, education, government, and others was studied by stilwell [10]. One of them is to make cleaning service work easier, especially in terms of moving goods in the form of glasses and plates, a control system is made that is able to receive orders from android was studied by irawan [11].

Previous research has been carried out on Designing Line Follower Goods Transfer Robot Based on the PIC16F877 Microcontroller was studies by liu [12]. In robot research using 2 infrared sensors, a motor driver to control 2 DC motors, a relay module as a motor controller to lift goods, a limi switch to stop the movement of the robot and the PIC16F877 microcontroller as the brain in this robot system was studied by ramadiansyah [13]. The robot in this study will move goods to a predetermined place using a black line. The overall system in this robot can function properly was studied by siregar [14].

In this research, a robot prototype will be designed that can move goods in the form of glasses and plates from one place to another using controls from android was studied by suyama [15].

\section{METHODS}

The research method used in this research is the method prototype method was studied by savin [16]. The steps to be carried out in this research based on the prototype method are:

\section{Gathering Needs}

This process will collect data from online interviews with the secretary of the Muara Bulian District Court to obtain data and literature study on various sources, the results of the interview are in the appendix was studied by tognon [17].

\section{Build Prototype}

Build prototyping using a simulator for modeling the system to be built was studied by anyaripour [18].

\section{Prototype Evaluation}

This evaluation is carried out by the customer whether the prototyping that has been built is in accordance with the customer's wishes. If it is appropriate then step 4 will be taken. If not prototyping is revised by repeating step 1 and was studied by yan [19]. 


\section{Encoding the System}

In this stage the prototyping that has been agreed upon by the respondent will be translated into an appropriate programming language and a suitable mechanical circuit was studied by howe [20].

\section{Testing the System}

After the hardware and software are synchronized, then test whether they are in accordance with the required requirements. Testing is done by conducting direct trials on the robot by making several attempts to move goods was studied by muhardi [21].

\section{System Evaluation}

Customers evaluate whether the system is as expected. If it is appropriate, proceed to step 7, otherwise, repeat steps 4 and 5 was studied by larochelle [22].

\section{Using the System}

The system is ready to be used and tested in the direct field and implemented was studied by xu [23].

\section{IMPLEMENTATION}

\section{A. Program Logic}

The program logic will explain in detail the parts of the program block and also the actions that will be given by the program block. This section will discuss 2 program logics to be used, namely hardware program logic and software program logic was studied by wahyuni [24].

\section{B. Hardware Program Logic}

The hardware program is used with the $\mathrm{C}$ programming language, which is a low-level language that is closely related to the microcontroller and the machine in this section will be divided into several parts, namely: infrared sensor reader, moving motor process, moving servo process, and rotating was studied by berkowitz [25].

\section{Sensor Reader}

Sensor readings are used to get the value or value from the sensor used, namely the infrared sensor. Digital pins are used for this sensor was studied by mohanraj [26]. Infrared sensor program code is described in Figure 1.

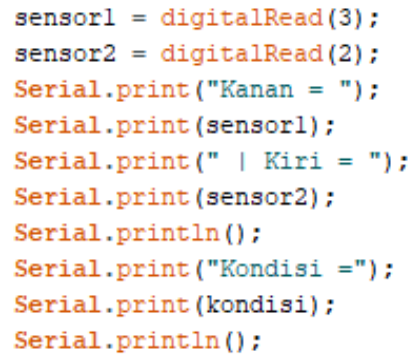

Fig. 1. Infrared Sensor Program Code

\section{Motor Driven}

The program code below explains how to make the motor move through the motor driver, the wheel will rotate if you get a High value and die if you get a Low value was studied by nugraha [27]. This motor program code is described in Figure 2.

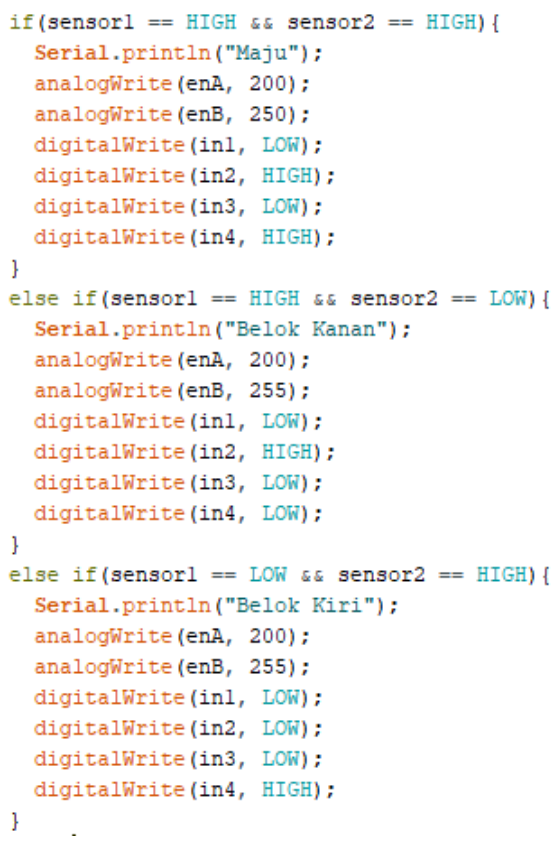

Fig. 2. Motor Program Code

\section{E. Implementation}

At this stage, the system implementation stage is carried out when the system is ready for use where the design process is ready to be carried out was studied by hwan [28].

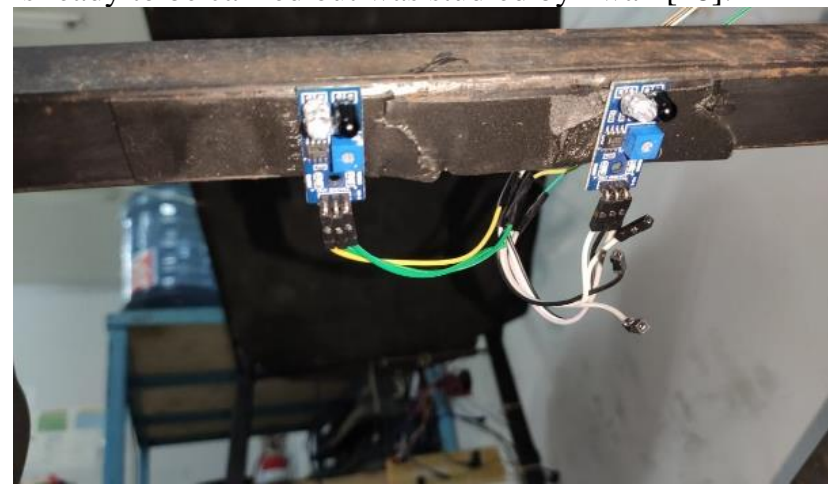

Fig. 3. Infrared Sensor

In Figure 3 There are 2 infrared sensors that have been installed in the robot's frame on the lower front of the robot.

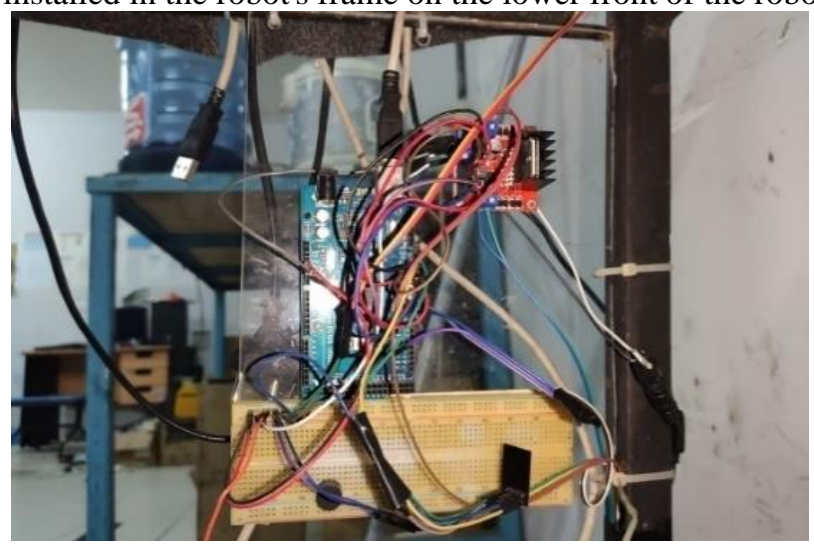

Fig. 4. Main Circuit 
In Figure 4, the main circuit in this robot is an Arduino, esp8266, a motor driver that is connected using a jumper cable from the module pin to the pin on the Arduino, the motor driver uses the digital pin on the Arduino to transmit data, esp8266 uses pins 2 and 3 to become RX and TX, digital pin 9 is used to drive the servo and pins A0 and A1 are for the infrared sensor was studied by wahyuni[29].

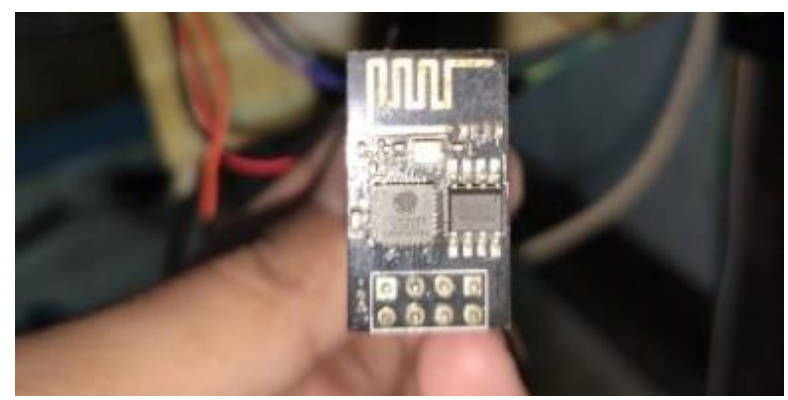

Fig. 4. Esp8266

In Figure 4 is the esp 8266 module for Arduino connection to WiFi so that it has the same network as the device for control.

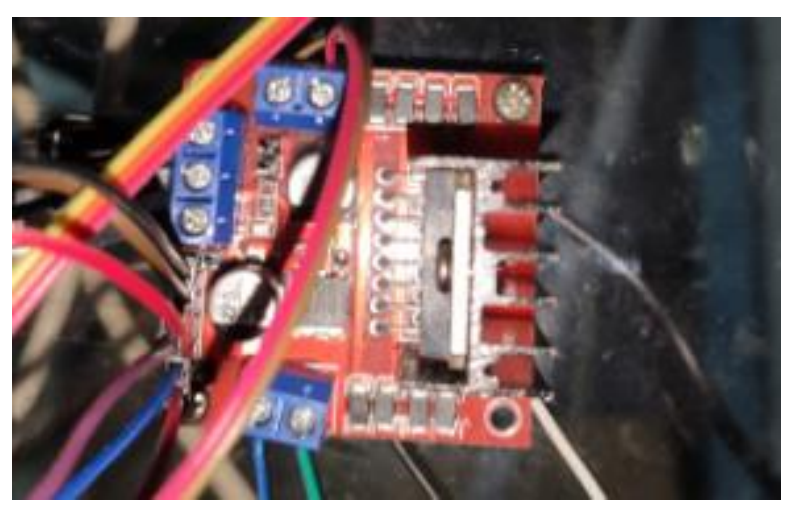

Fig. 5. Motor Driver

In Figure 5 is a module that will connect a dc motor with Arduino and also connect to $12 \mathrm{v}$ power or electricity.

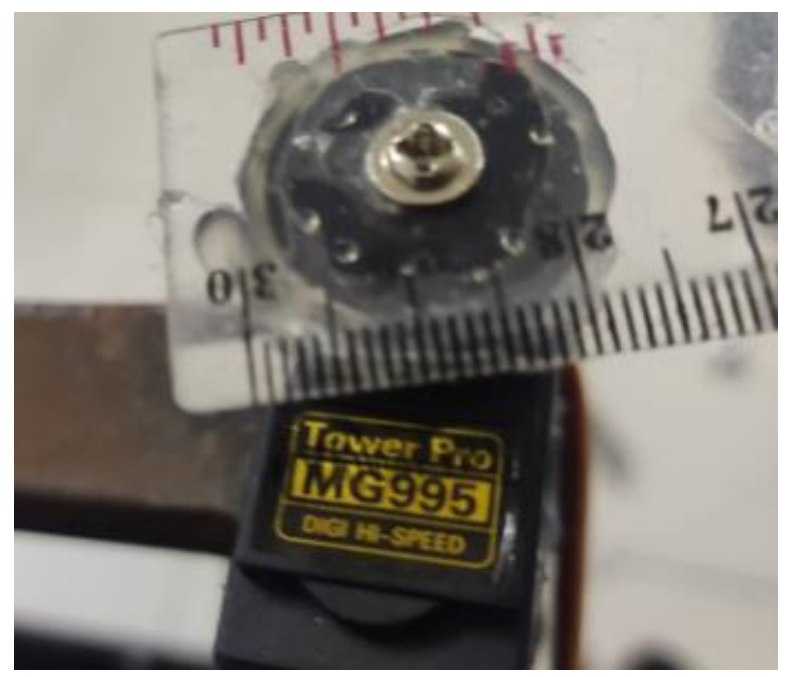

Fig. 6. Servo

In Figure 6 is a servo that is used to drop plates and glasses from the table and will be shifted into the robot.

\section{F. Test result}

Testing is done by testing the work of the robot in taking glasses / bottles and plates and bringing them back. In this study, researchers conducted a study of 10 times so that the data obtained will be described in Table 1 .

Table 1. System Testing Table

\begin{tabular}{|c|c|c|c|}
\hline $\begin{array}{c}\text { Test } \\
\text { Number }\end{array}$ & $\begin{array}{c}\text { Go to } \\
\text { the } \\
\text { table }\end{array}$ & $\begin{array}{c}\text { Take the } \\
\text { glass / } \\
\text { plate }\end{array}$ & Back home \\
\hline 1 & Success & Failed & Failed \\
\hline 2 & Success & Success & Failed \\
\hline 3 & Failed & Failed & Failed \\
\hline 4 & Success & Success & Gagal \\
\hline 5 & Success & Success & Berhasil \\
\hline 6 & Success & Success & Berhasil \\
\hline 7 & Success & Success & Berhasil \\
\hline 8 & Success & Success & Berhasil \\
\hline 9 & Failed & Failed & Failed \\
\hline 10 & Success & Success & Success \\
\hline
\end{tabular}

From Table 1 gets the conclusion that if the successful experiment without failure is $50 \%$ of the total 10 experiments that have been carried out. From the observation of robot failure, there are several factors, namely: sandy terrain, unstable sensor data in reading the lines or paths that have been made and also the motor speed which depends on the power obtained from the power supply was studied by pahuja [30].

From the results of the research the authors can draw conclusions from systems that have advantages and disadvantages, namely:

A. Advantages

1. Can move independently without having to be controlled manually.

2. Be able to move plates and glasses without breaking them.

3. Helping the work of customer service in terms of taking the glasses and plates used by employees.

B. Disadvantages

1. Using a path that can pollute the floor if opened or not used anymore.

2. The battery should be checked frequently as it affects the performance of the motor and other devices.

3. Move to all tables even though there are no glasses / plates on the table.

\section{CONCLUSION}

From the results of experiments and observations made on robot development, the following conclusions are obtained this system or robot can work as expected, the system is capable of mapping based on the path that has been made. The robot is also able to take a glass / plate from the table to move it to the desired place was studied by zheng[31]. From the experiments that have been done, it is obtained a value of $50 \%$ success rate from all series of experiments that must be passed. Robots can help with cleaning services because they can move glasses and plates from the employee 
room to the pantry room. Improve the motor part to make it more stable even though there is a decrease in power by adding a stabilizer to the motor power was studied by liu [32].

\section{REFERENCES}

[1] J. Zhu, Y. Wang and H. Zhou, "Human-machine coupling control of exoskeleton intelligent load carry robot," 2012 IEEE International Conference on Mechatronics and Automation, Chengdu, 2012, pp. 268-272, doi: 10.1109/ICMA.2012.6282853.

[2] Dong-Jun Kim, Kab Kim Il, Y. F. Zheng, Zengqi Sun and Fuchun Sun, "Design of small power biped robot by load sharing of walking gait," Proceedings 2000 ICRA. Millennium Conference. IEEE International Conference on Robotics and Automation. Symposia Proceedings (Cat. No.00CH37065), San Francisco, CA, USA, 2000, pp. 3359-3364 vol.4, doi: 10.1109/ROBOT.2000.845231.

[3] K. Kosuge, T. Oosumi and K. Chiba, "Load sharing of decentralizedcontrolled multiple mobile robots handling a single object," Proceedings of International Conference on Robotics and Automation, Albuquerque, NM, USA, 1997, pp. 3373-3378 vol.4, doi: 10.1109/ROBOT.1997.606803.

[4] Irawan, Yuda. "Implementation Of Data Mining For Determining Majors Using K-Means Algorithm In Students Of SMA Negeri 1 Pangkalan Kerinci." Journal of Applied Engineering and Technological Science (JAETS) 1.1 (2019): 17-29.

[5] Bahrami, M. R., \& Abed, S. A. Mechanics Of Robot Inspector On Electrical Transmission Lines Conductors: Performance Analysis Of Dynamic Vibration Absorber. Vibroengineering Procedia, 2019, 25, 60-64.

[6] Zhu, H., Wang, B., \& Zhao, M. Coupling Dynamic Response Analysis Of Truss Robot Under Moving Load. In 2017 2nd International Conference On Advanced Robotics And Mechatronics (ICARM), 2017, (Pp. 264-269). IEEE.

[7] ZHOU, Tiger TG; ZHOU, Dylan TX; ZHOU, Andrew HB. Unmanned Drone, Robot System For Delivering Mail, Goods, Humanoid Security, Crisis Negotiation, Mobile Payments, Smart Humanoid Mailbox And Wearable Personal Exoskeleton Heavy Load Flying Machine. U.S. Patent Application No 14/285,659, 2014.

[8] CHOI, Doo-Jin, Et Al. Multi-Function Robot For Moving On Wall Using Indoor Global Positioning System. U.S. Patent No 8,214,081, 2012 .

[9] Nascimento, T. P., Moreira, A. P., \& Conceição, A. G. S. Multi-Robot Nonlinear Model Predictive Formation Control: Moving Target And Target Absence. Robotics And Autonomous Systems, 2013, 61(12), 1502-1515.

[10] D. J. Stilwell and J. S. Bay, "Toward the development of a material transport system using swarms of ant-like robots, " [1993] Proceedings IEEE International Conference on Robotics and Automation, Atlanta, GA, USA, 1993, pp. 766-771 vol.1, doi: 10.1109/ROBOT.1993.292070.

[11] Irawan, Y., Fernando, Y., \& Wahyuni, R. Detecting Heart Rate Using Pulse Sensor as Alternative Knowing Heart Condition. Journal of Applied Engineering and Technological Science (JAETS),2019, 1(1), pp 30-42.

[12] C. Liu, W. Cai, T. Xia, Y. Wang and H. Ni, "A Study of the Robot Loading/Unloading Unit Based on the Optimized Automatic Verification System of Electric Meters," 2017 4th International Conference on Information Science and Control Engineering (ICISCE), Changsha, 2017, pp. 816-820, doi: 10.1109/ICISCE.2017.174

[13] M. Ramadiansyah, W. Wahab and Nasril, "Modelling, simulation and control of a high precision loading-unloading robot for CNC milling machine," 2017 15th International Conference on Quality in Research (QiR): International Symposium on Electrical and Computer Engineering, Nusa Dua, 2017, pp. 204-208, doi: 10.1109/QIR.2017.8168482.

[14] M. F. Siregar, P. Sihombing and Suherman, "Analysis of Fuzzy Logic Method for Load Lifting Robot," 2019 3rd International Conference on Electrical, Telecommunication and Computer Engineering (ELTICOM), Medan, Indonesia, 2019, pp. 125-129, doi: 10.1109/ELTICOM47379.2019.8943852.
[15] Suyama, T., Nakamura, T., Kouno, D., Nishimura, T., Matsuo, T., Ishikawa, S., \& Kawano, T. U.S. Patent No. 9,162,359. Washington, 2015, DC: U.S. Patent And Trademark Office.

[16] Savin, S., Jatsun, S., \& Vorochaeva, L. Trajectory Generation For A Walking In-Pipe Robot Moving Through Spatially Curved Pipes. In MATEC Web Of Conferences (2017, Vol. 113, P. 02016). EDP Sciences.

[17] Tognon, M., \& Franchi, A. Position Tracking Control For An Aerial Robot Passively Tethered To An Independently Moving Platform. IFAC-Papersonline, 2017, 50(1), 1069-1074.

[18] Anvaripour, M., Khoshnam, M., Menon, C., \& Saif, M. Safe Human Robot Cooperation In Task Performed On The Shared Load. In 2019 International Conference On Robotics And Automation (ICRA), 2019 (Pp. 3761-3767). IEEE.

[19] Yan, Z., Jouandeau, N., \& Ali-Chérif, A. Multi-Robot Heuristic Goods Transportation. In 2012 6th IEEE International Conference Intelligent Systems, 2012 (Pp. 409-414). IEEE.

[20] R. D. Howe, I. Kao and M. R. Cutkosky, "The sliding of robot fingers under combined torsion and shear loading," Proceedings. 1988 IEEE International Conference on Robotics and Automation, Philadelphia, PA, USA, 1988, pp. 103-105 vol.1, doi: 10.1109/ROBOT.1988.12032.

[21] Muhardi, Muhardi, et al. "Design Of Web Based LMS (Learning Management System) in SMAN 1 Kampar Kiri Hilir." Journal of Applied Engineering and Technological Science (JAETS) 1.2 (2020): 70-76.

[22] P. Larochelle and J. M. McCarthy, "Performance evaluation of cooperating robot movements using maximum load under timeoptimal control," Proceedings. 1991 IEEE International Conference on Robotics and Automation, Sacramento, CA, USA, 1991, pp. 26122617 vol.3, doi: 10.1109/ROBOT.1991.132022.

[23] Z. Xu, X. Bai, J. Wang, M. Liu and X. Zhang, "The Control Method of Force Loading of Robot on Load Transfer Mechanism of Space Station," 2019 IEEE 15th International Conference on Control and Automation (ICCA), Edinburgh, United Kingdom, 2019, pp. 518-523, doi: 10.1109/ICCA.2019.8899496.

[24] Wahyuni, Refni; Irawan, Yuda. Web-Based Heart Disease Diagnosis System With Forward Chaining Method (Case Study Of Ibnu Sina Islamic Hospital). Journal Of Applied Engineering And Technological Science (Jaets), 2019, 1.1: 43-50.

[25] Berkowitz, Ben; Rosmarin, Josiah. Management Of Cables That Traverse Moving Robot Joints. U.S. Patent Application No 13/446,585, 2013.

[26] Mohanraj, D. Microcontroller Based An Autonomous Wireless Line Tracking Robot. Int. J. Adv. Engg. Res. Studies/III/III/April-June, 2014, 102, 105.

[27] Nugraha, M. B., Ardianto, P. R., \& Darlis, D. Design And Implementation Of RFID Line-Follower Robot System With Color Detection Capability Using Fuzzy Logic. In 2015 International Conference On Control, Electronics, Renewable Energy And Communications (ICCEREC), 2015 (Pp. 75-78). IEEE.

[28] Hwan Taek Ryu, Jae Yeon Choi, Byung-Ju Yi, Jiseok Lee, Dae Je Kim and Jisung Ko, "Human-robot integrated model of upperextremity," 2012 9th International Conference on Ubiquitous Robots and Ambient Intelligence (URAI), Daejeon, 2012, pp. 7-9, doi: 10.1109/URAI.2012.6462917.

[29] Wahyuni, Refni; Irawan, Yuda. Web-Based Employee Performance Assessment System in PT. Wifiku Indonesia. Journal of Applied Engineering and Technological Science (JAETS), 2020, 1.2: 60-69.

[30] Pahuja, R., \& Kumar, N. Android Mobile Phone Controlled Bluetooth Robot Using 8051 Microcontroller. International Journal Of Scientific Engineering And Research, 2015, 2(7), 14-17.

[31] Y. F. Zheng and J. Y. S. Luh, "Optimal load distribution for two industrial robots handling a single object," Proceedings. 1988 IEEE International Conference on Robotics and Automation, Philadelphia, PA, USA, 1988, pp. 344-349 vol.1, doi: 10.1109/ROBOT.1988.12072.

[32] H. Liu, C. Luo and L. Zhang, "Target Recognition and Heavy Load Operation Posture Control of Humanoid Robot for Trolley Operation," 2018 IEEE-RAS 18th International Conference on Humanoid Robots (Humanoids), Beijing, China, 2018, pp. 280-283, doi: 10.1109/HUMANOIDS.2018.8625056. 